AperTO - Archivio Istituzionale Open Access dell'Università di Torino

\title{
Functional involvement of the cerebral cortex following paramedian bithalamic infarction
}

\section{This is the author's manuscript}

Original Citation:

Availability:

This version is available http://hdl.handle.net/2318/79482

since

Published version:

DOI:10.1080/13554790903463593

Terms of use:

Open Access

Anyone can freely access the full text of works made available as "Open Access". Works made available under a Creative Commons license can be used according to the terms and conditions of said license. Use of all other works requires consent of the right holder (author or publisher) if not exempted from copyright protection by the applicable law. 


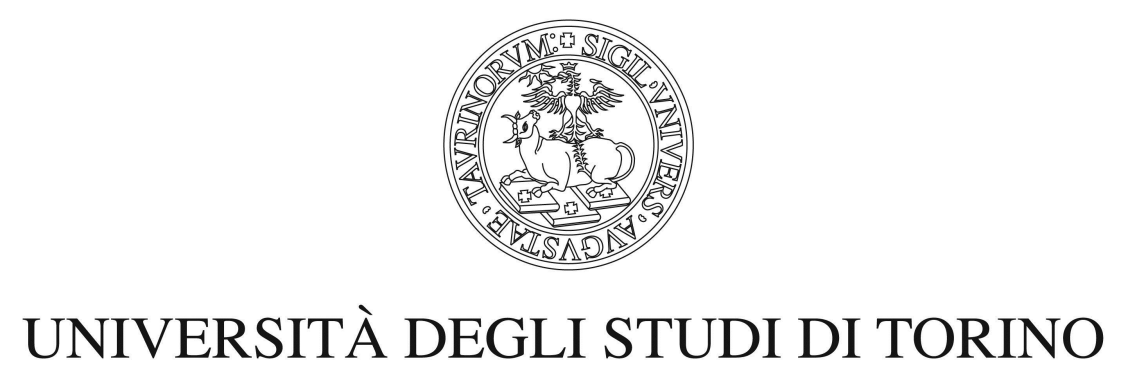

This is an author version of the contribution published on:

Raffaele Nardone, Jürgen Bergmann, Martin Kronbichler, Pierpaolo De Blasi, Francesca Caleri, Frediano Tezzon, Gunther Ladurner and Stefan

Golaszewski. Functional involvement of the cerebral cortex following paramedian bithalamic infarction. Neurocase, Volume 16, Issue 4, Pages 286-292, 2010, DOI 10.1080/13554790903463593.

The definitive version is available at:

www.tandfonline.com/doi/full/10.1080/13554790903463593 


\title{
Functional involvement of the cerebral cortex following paramedian bithalamic infarction
}

\author{
Raffaele Nardone, ${ }^{1,2}$ Jürgen Bergmann, ${ }^{2}$ Martin Kronbichler, \\ Pierpaolo De Blasi, ${ }^{3}$ Francesca Caleri, ${ }^{1}$ Frediano Tezzon, ${ }^{1}$ \\ Gunther Ladurner, ${ }^{2}$ and Stefan Golaszewski ${ }^{2}$ \\ ${ }^{1}$ Department of Neurology, Franz Tappeiner Hospital, Meran/o, Italy \\ ${ }^{2}$ Institute of Neurology, Christian Doppler Clinic, Paracelsus Private Medical University, \\ Salzburg, Austria \\ ${ }^{3}$ Department of Statistics and Applied Mathematics, Collegio Carlo Alberto, University of \\ Turin, Torino, Italy
}

\begin{abstract}
To investigate further the functional mechanisms underlying the so-called 'loss of psychic self-activation' following paramedian bithalamic lesions, we used transcranial magnetic stimulation (TMS) in a patient who presented with this clinical picture after paramedian bithalamic infarction due to arterial occlusion. The patient showed higher motor thresholds than the controls; the cortical silent period and intracortical inhibition to paired-pulse stimulation, two different forms of inhibition that are believed to reflect GABAergic mechanisms, were significantly increased; short latency afferent inhibition (SAI), a technique that may give direct information about the function of some cholinergic circuits in the human brain, was significantly reduced. This study first demonstrates that there are changes in the intracortical excitatory and inhibitory circuits in this neurobehavioral syndrome, that lead to cortical hypoexcitability. The modulation in GABAergic activity may result in excitability changes in those cholinergic cortical networks that are involved in SAI. TMS may provide important information on connections between the thalamus and cortex and may help in better understanding the role of the thalamo-cortical relationship in behavioural changes associated with thalamic stroke.
\end{abstract}

Keywords: Bithalamic infarction; Psychic self-activation; Transcranial magnetic stimulation cortical silent period; Short latency intracortical inhibition; Short latency afferent inhibition.

\section{INTRODUCTION}

The syndrome of emotional blunting, loss of initiative and absence of spontaneous thoughts or mental activities, conceptualized as 'loss of psychic selfactivation', has been described after bilateral lesions to the globus pallidus, striatum and white matter of the frontal lobes (Habib \& Poncet, 1988; Laplane, Baulac, Widlöcher, \& Dubois, 1984), but has rarely been reported in patients with bithalamic lesions (Bogousslavsky et al., 1991; Engelborghs,
Marien, Pickut, Verstraten, \& De Deyn, 2000). The exact functional-anatomical mechanisms underlying loss of psychic self-activation in these patients remain to be elucidated.

To determine whether this neurobehavioral syndrome is associated with changes in cortical excitability, we examined a number of excitatory and inhibitory cortical circuits through different transcranial magnetic stimulation (TMS) paradigms in a patient who presents with loss of psychic self-activation after recovery from acute-phase

Address correspondence to Dr Raffaele Nardone, Department of Neurology, 'F. Tappeiner' Hospital, Merano, Via Rossini, 5, 39012, Meran/o (BZ), Italy. (E-mail: raffaele.nardone@asbmeran-o.it).

(C) 2010 Psychology Press, an imprint of the Taylor \& Francis Group, an Informa business 
symptomatology of a bilateral paramedian thalamic infarction.

\section{MATERIALS AND METHODS}

\section{Patient}

The 46-year-old woman developed acutely changes in her mental status manifested by drowsiness and altered levels of consciousness. On admission to hospital she was responsive to occasional verbal stimulus. Brain magnetic resonance imaging (MRI) revealed acute infarcts in the paramedian thalamic region, involving mainly the dorsomedian nucleus (Figure 1a). During hospitalisation, the patient gradually recovered her normal mental status, but developed marked behavioural changes in the absence of sensorimotor deficits. Somatosensory evoked potentials (SEPs) recorded from upper and lower limbs were bilaterally normal. She had no history of smoking and used no medication apart from oral contraceptives. Full laboratory investigations were negative for all currently known varieties of thrombophilia and autoimmune disorders. Transesophageal echocardiography was unrevealing and Holter-electrocardiogram monitoring failed to show atrial fibrillation. Thirteen months after her stroke, the clinical examination revealed an athymic syndrome characterized by apathy, indifference, poor motivation and flattened affect with marked absence of thoughts and spontaneous mental activity. She took no verbal initiative and the neurolinguistic profile disclosed a slightly reduced verbal fluency; a discrete general memory disorder was objectified by means of the revised Wechsler memory Scale (Wechsler, 1987). The patient was slightly hypersomnic with $10-12 \mathrm{~h}$ of sleep behaviour per day. Concentration and sustained attention were also impaired; the remainder of the neuropsychological examination was within normal limits. At that time, the follow-up MRI examination showed only a slight reduction of the parenchymal lesions (Figure 1b). Follow-up neuropsychological examination two years after the onset of symptoms still revealed identical personality changes with loss of self-activation and a slight worsening of the mnemonic disturbances. Specific laboratory investigations were performed to exclude immunologic or metabolic changes in the cerebral cortex due to systemic diseases revealed during disease evolution. In particular, we performed the laboratory tests to exclude acquired

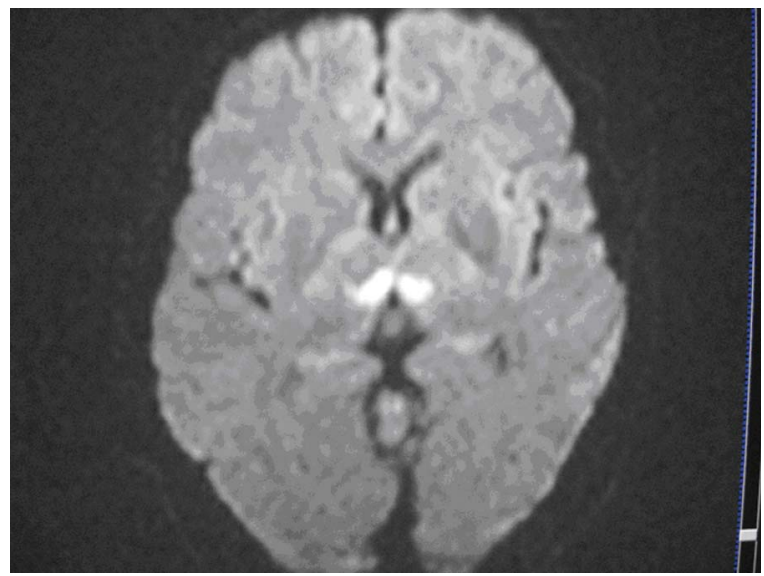

(a)

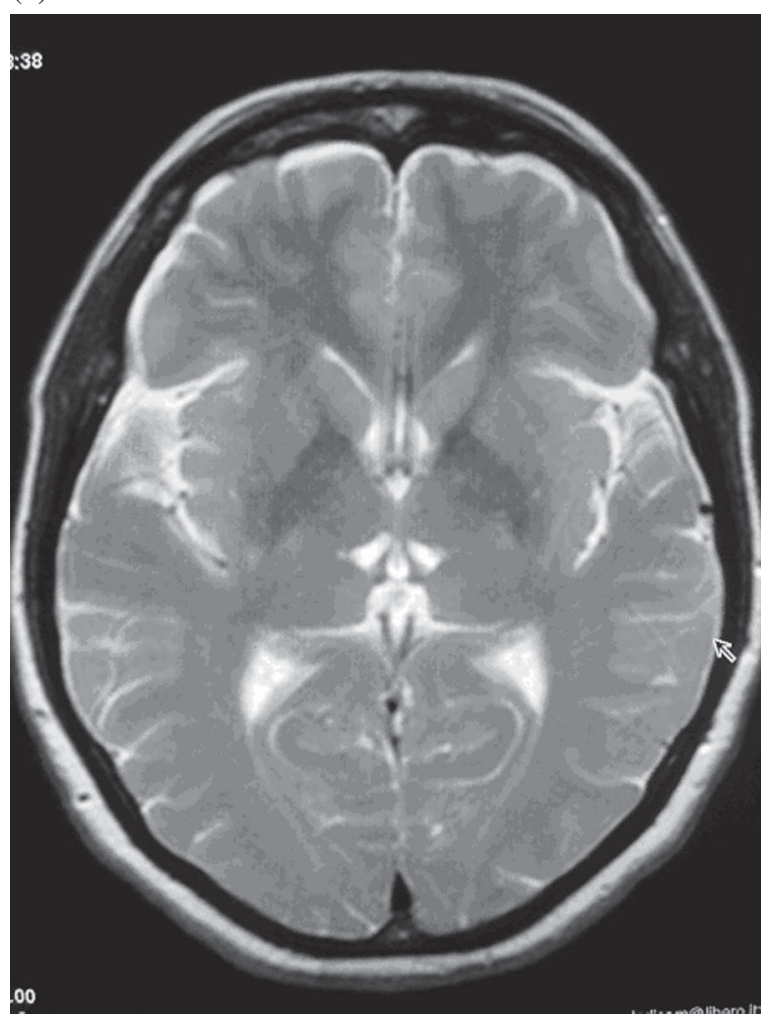

(b)

Figure 1. (a) Diffusion-weighted magnetic resonance (MR) images showed abnormal hyperintense lesions in the paramedian thalamic region, consistent with acute ischemic events. (b) Follow-up examination 13 months after onset of the illness: T2weighted MR images showed only a slight reduction of the bithalamic paramedian lesions.

metabolic diseases of the nervous system such as hepatic and uremic encephalopathy, encephalopathies due to electrolyte and endocrine disturbances, autoimmune diseases of the nervous system such as demyelinating autoimmune diseases, vasculitis of 
CNS, systemic lupus erythematosus, antiphospholipid syndrome, autoimmune thyroiditis, myasthenia gravis.

\section{Transcranial magnetic stimulation}

TMS was performed 13 months and two years after onset of illness using a high-power Magstim 200 magnetic stimulator. A figure-of-eight coil with external loop diameters of $9 \mathrm{~cm}$ was held over the motor cortex at the optimum scalp position to elicit motor responses in the contralateral first dorsal interosseous (FDI) muscle. Both hemispheres were subsequently examined in the patient and in the control subjects. Motor evoked potentials (MEPs) were recorded via two 9-mm diameter $\mathrm{Ag}_{-}$ $\mathrm{AgCl}$ electrodes with the active electrode applied over the motor point of the muscle and the reference on the metacarpophalangeal joint of the index finger.

The first examination included the following TMS parameters: threshold and amplitude of MEPs, the central motor conduction time (CMCT) and the cortical silent period (CSP). Two years after onset of disease, the short latency intracortical inhibition (SICI) to paired TMS, the intracortical facilitation (ICF) to paired TMS and the short latency afferent inhibition (SAI) were also evaluated.

Resting motor threshold (RMT) was defined as the minimum stimulus intensity that produced a liminal motor evoked response (about $50 \mu \mathrm{V}$ in $50 \%$ of 10 trials) at rest. Active motor threshold (AMT) was defined as the minimum stimulus intensity that produced a liminal motor evoked response (about $200 \mu \mathrm{V}$ in $50 \%$ of 10 trials) during isometric contraction of the tested muscle at about $10 \%$ maximum. We evaluated the excitability of the motor cortex at increasing stimulus intensity by measuring the average response to five stimuli at $100 \%$ AMT, $150 \%$ AMT and 200\% AMT during a $50 \%$ maximum contraction. Central motor conduction was calculated by subtracting the peripheral conduction time from spinal cord to muscles from the latency of responses evoked by cortical stimulation, with the formula: MEP latency - (F latency + M latency -1$) / 2$ (Rossini et al., 1994). The CSP was elicited whilst subjects held a tonic voluntary contraction of approximately $20 \%$ of maximum voluntary contraction. Five stimuli at $150 \%$ AMT were given. CSP duration was measured from the end of the EMG response to the return of post-stimulus EMG activity.
Intracortical inhibition and facilitation were studied using the technique of Kujirai et al. (1993). Using a Bistim module, two magnetic stimuli were given through the same stimulating coil over the motor cortex, and the effect of the first (conditioning) stimulus on the second (test) stimulus was investigated. The intensity of the first pulse was set to $90 \%$ AMT, and the second pulse was adjusted to produce an unconditioned MEP of an average $1 \mathrm{mV}$.

The timing of the conditioning shock was altered in relation to the test shock. Inhibitory interstimulus intervals (ISIs) of 2 and $3 \mathrm{~ms}$ and facilitatory ISIs of 10 and $20 \mathrm{~ms}$ were investigated. Ten stimuli were delivered at each ISI. For these recordings, muscle relaxation is very important and the subject was given audiovisual feedback at high gain to assist in maintaining complete relaxation. The presentation of conditioned and unconditioned trials was randomised. The amplitude of the conditioned EMG responses was expressed as the percentage of the amplitude of the test EMG responses. The amplitudes of the conditioned responses at the two different inhibitory ISIs and the amplitudes of the conditioned responses at the two different excitatory ISIs were averaged obtaining mean amplitudes of each inhibitory ISI and each facilitatory ISI.

SAI was studied using the recently described technique (Tokimura et al., 2000). Conditioning stimuli were single pulses $(200 \mu$ s) of electrical stimulation (with the cathode positioned proximally) applied through bipolar electrodes to the median nerve at the wrist. The intensity of the conditioning stimuli was set at just over motor threshold for evoking a visible twitch of the thenar muscles. The intensity of the test cortical magnetic shock was adjusted to evoke a muscle response in relaxed FDI with an amplitude of approximately $1 \mathrm{mV}$ peak-topeak. The conditioning stimulus to the peripheral nerve preceded the test magnetic cortical stimulus. Interstimulus intervals (ISIs) were determined relative to the latency of the N20 component of the somatosensory evoked potential evoked by stimulation of the median nerve. The active electrode for recording the $\mathrm{N} 20$ potential was attached $3 \mathrm{~cm}$ posterior to $\mathrm{C} 3$ (10-20 system), and the reference was 3 $\mathrm{cm}$ posterior to $\mathrm{C} 4$. Five hundred responses were averaged to identify the latency of the N20 peak. ISIs from the latency of the N20 component plus 2 $\mathrm{ms}$ to the latency of the $\mathrm{N} 20$ component plus $8 \mathrm{~ms}$ were investigated in steps of $1 \mathrm{~ms}$.

Five stimuli were delivered at each ISI. We calculated an average of the MEP obtained after cortical magnetic stimulation alone and of the MEP 
obtained by conditioning cortical magnetic stimulus with a peripheral stimulus to the median nerve at the wrist at the seven different ISIs studied. The amplitude of the conditioned MEP was expressed as percentage of the amplitude of the test MEP. The percentage inhibition of the conditioned responses at the seven different ISIs was averaged to obtain a grand mean. Subjects were given audiovisual feedback at high gain to assist in maintaining complete relaxation.

Additionally, supramaximal stimulation of the ulnar nerve at the wrist was used to assess spinal and peripheral motor excitability; while FDI was relaxed, the peak-to-peak amplitude of $F$ waves (average, 20 trials) and CMAP (maximum, 3 trials) were determined.

Ten age-matched healthy volunteers (four women and six men; mean age 55.5 years, range 35-64 years) represented the control population.

\section{Statistical analysis}

In order to assess whether the neurophysiological parameters of the patient are statistically different from those of the control group, we used the data of the control group to derive prediction intervals for each neurophysiological parameter and then checked if the corresponding value of the patient is captured by the prediction interval. If this is not the case, we draw the conclusion that the patient cannot be assimilated to a healthy subject with respect to the neurophysiological parameter under consideration. Such analysis is based on the assumption that the values for each neurophysiological parameter of the control group represent an independent and identically distributed sample from a normal population with unknown mean and variance. This allowed us to compute a $100 \times$ $p \%$ prediction interval as $m \pm t_{(1+p) / 2} \times S \times(1+1 /$ $n)^{1 / 2}$, where $m$ stands for the sample mean, $S$ is the corrected sample standard deviation and $t_{(1+p) / 2}$ is the $100 \times(1+p) / 2$ the percentile of a Student's $t$-distribution with $n-1$ degrees of freedom.

\section{RESULTS}

At the first examination 13 months after the beginning of the symptoms, both RMT and AMT were bilaterally increased, and the amplitude of motor responses during voluntary activity was bilaterally reduced in the patient, but only RMT differences were statistically significant. CMCT was bilaterally in the normal limits. The patient showed a significantly prolonged CSP duration in both hemispheres when compared with the controls.

At the second examination two years after onset of the illness, these results remained substantially unchanged. At this time also the SICI and ICF to paired TMS and the SAI were examined. The SICI was significantly increased in both hemispheres, while ICF did not differ significantly between the patient and the controls. SAI was significantly reduced in both hemispheres.

Motor cortex excitability measurements together with the $99 \%$ prediction intervals for the control group are reported in Table 1.

\section{DISCUSSION}

Infarcts in the paramedian territory involve mainly the dorsomedian and intralaminar nuclei. The dorsomedian nucleus receives projections from the amygdala and has connections to the prefrontal cortex and ventral pallidum (Giguere \& GoldmanRakic, 1988). The intralaminar nuclei project to the orbitofrontal and mediofrontal cortex, the motor and premotor cortex and the internal globus pallidus (Groenewegen \& Berendse, 1994). After paramedian strokes several distinct personality changes resulting from thalamofrontal disconnection have been reported. SPECT data suggest that the loss of psychic self-activation after bithalamic paramedian infarction may be caused by bilateral disruption at different levels of the striatal-ventral pallidal-thalamic-frontomesial loop (Engelborghs et al., 2000).

Thalamic lesions have been reported to be associated with shorter or prolonged CSP depending on the lesion location (Classen et al., 1997; Liepert, Restmeyer, Munchau, \& Weiller, 2005; Munchau et al., 2002). Neuroanatomically, there are dense connections between thalamus and the primary sensory cortex (Darian-Smith \& Darian-Smith, 1993), as well as between thalamus and primary motor cortex (Darian-Smith, Darian-Smith, \& Cheema, 1990). It has been hypothesised (Liepert et al., 2005) that sensory output could have, physiologically, an inhibitory or excitation-limiting effect on the motor cortex. However, sensory testing, SEP measurements and MRI findings showed that the somatosensory thalamocortical pathways are not affected by paramedian thalamic strokes. 
TABLE 1

Electrophysiological data of the patient and the control subjects

\begin{tabular}{|c|c|c|c|c|c|c|}
\hline \multirow[b]{3}{*}{ TMS measures } & \multicolumn{4}{|c|}{ Patient } & & \\
\hline & \multicolumn{2}{|c|}{$R H$} & \multicolumn{2}{|c|}{$L H$} & \multicolumn{2}{|c|}{ Control subjects } \\
\hline & $1^{\circ}$ & $2^{\circ}$ & $1^{\circ}$ & $2^{\circ}$ & $R H$ & $L H$ \\
\hline CMCT (ms) & 6.1 & 6.2 & 6.5 & 6.5 & $6.0 \pm 1.4$ & $6.1 \pm 1.5$ \\
\hline RMT (\% MSO) & 64 & 63 & 62 & 62 & $45.5 \pm 13.9$ & $46.2 \pm 14.2$ \\
\hline AMT (\% MSO) & 47 & 47 & 46 & 47 & $35.2 \pm 14.3$ & $35.6 \pm 13.4$ \\
\hline MEP АMT $100 \%(\mu \mathrm{V})$ & 195 & 202 & 187 & 190 & $235 \pm 161$ & $222 \pm 169$ \\
\hline MEP AMT $150 \%(\mathrm{mV})$ & 1.2 & 1.2 & 1.1 & 1.1 & $1.9 \pm 1.4$ & $1.8 \pm 1.2$ \\
\hline MEP AMT $200 \%(\mathrm{mV})$ & 2.1 & 2.2 & 1.9 & 2.0 & $2.9 \pm 1.6$ & $2.7 \pm 1.8$ \\
\hline $\mathrm{CSP}(\mathrm{ms})$ & 235 & 238 & 244 & 246 & $156.6 \pm 38.6$ & $161.2 \pm 37.4$ \\
\hline SICI 2 ms ( $\%)$ & & 12.4 & & 14.2 & $24.8 \pm 12.4$ & $25.2 \pm 13.6$ \\
\hline SICI 3 ms (\%) & & 15.6 & & 16.7 & $30.8 \pm 14.8$ & $30.8 \pm 14.8$ \\
\hline ICF 10 ms (\%) & & 116.2 & & 117.4 & $122.6 \pm 32.6$ & $120.8 \pm 34.5$ \\
\hline ICF $20 \mathrm{~ms}(\%)$ & & 112.5 & & 113.7 & $115.6 \pm 28.8$ & $114.4 \pm 30.2$ \\
\hline SAI $(\%)$ & & 68.4 & & 70.2 & $46.4 \pm 14.2$ & $46.6 \pm 15.4$ \\
\hline CMAP (mV) & 10.2 & 10.3 & 10.5 & 10.4 & $10.5 \pm 4.6$ & $10.8 \pm 4.8$ \\
\hline F-wave $(\mu \mathrm{V})$ & 215 & 222 & 224 & 228 & $216.4 \pm 104.2$ & $220.6 \pm 106.9$ \\
\hline
\end{tabular}

The data of the control group are reported in terms of $99 \%$ prediction intervals. The data of the patient are reported in bold if they are not captured by the $99 \%$ prediction interval, in normal font otherwise.

Legend: LH, left hemisphere; RH, right hemisphere; $1^{\circ}$, first examination; $2^{\circ}$, second examination; CMCT, central motor conduction time; RMT, resting motor threshold; AMT, active motor threshold; MSO, maximum stimulator output; MEP, motor evoked potential; CSP, cortical silent period; SICI, short latency intracortical inhibition; ICF, intracortical facilitation; SAI, short latency afferent inhibition; CMAP, compound motor action potential.

Using TMS, we found hypoexcitability of excitatory circuits (increased motor thresholds) and enhanced activity of cortical inhibitory circuits (prolonged CSP duration and increased SICI) in our patient. The results of the present study could represent a special inhibitory cortical state and a similar functional state could be found in other thalamic-striatal connections such as basal frontalmesial structures, but specific studies documenting this phenomenon are lacking. Based on this assumption, these functional changes could be the possible mechanism underlying the loss of psychic self-activation syndrome. However, further studies of a large number of patients with thalamic stroke are warranted; at the present the exact pathophysiological mechanisms remain speculative.

Threshold and amplitudes of MEP reflect the intrinsic and extrinsically modulated excitability properties of corticospinal neurons (Hallett, 2000). Since SICI as well as CSP reflect the activity of GABAergic inhibitory circuits (Di Lazzaro et al., 2000; Sanger, Garg, \& Chen, 2001; Werhahn, Kunesch, Noachtar, Benecke, \& Classen, 1999; Ziemann, Lonnecker, Steinhoff, \& Paulus, 1996), the increase of CSP duration and SICI might be the expression of an enhanced excitability of the inhibitory GABA-controlled interneuronal circuits in the motor cortex due to a lack of inhibitory control usually exerted by the thalamocortical projections.

In agreement with our findings, Oliviero et al. (2005) previously reported a reduced ipsilateral SAI in a patient with unilateral stroke of the paramedian thalamus. The loss of SAI suggests that intact paramedian thalamus facilitates intracortical inhibitory circuits which process thalamocortical sensory inputs in the ipsilateral motor cortex. SAI is produced by interactions between the cerebral cortex (Di Lazzaro et al., 2004; Tokimura et al., 2000) and is thought to be related to central cholinergic activity because in healthy subjects it can be reduced or abolished by intravenous injection of scopolamine and is positively modulated by acetylcholine (ACh) (Di Lazzaro et al., 2005a, 2006).

This reduction in SAI may be explained by an inhibition in ACh release due to the enhancement of GABAergic activity. GABA is known to affect cholinergic transmission at multiple central nervous system levels (Giorgetti et al., 2000). GABA antagonists enhance release of ACh at the level of the cerebral cortex (Diez-Ariza, Garcia-Alloza, 
Lasheras, Del Rio, \& Ramirez, 2002; Giorgetti et al., 2000) and at the forebrain level (Vasquez \& Baghdoyan, 2003); $\mathrm{GABA}_{\mathrm{A}}$ receptors are localized on forebrain cholinergic neurons projecting to the cortex (Zaborszky, Heimer, Eckenstein, \& Leranth, 1986), and their activation results in inhibition (Khateb et al., 1998). It has been recently demonstrated (Di Lazzaro et al., 2005b) that the administration of lorazepam produces a significant increase in SICI and a significant decrease of SAI in normal subjects. It could therefore be hypothesised that in subjects with paramedian thalamic lesions GABAergic activity enhancement determines a suppression of central cholinergic activity, as evaluated by means of SAI.

Together with imaging techniques, TMS will help in understanding the impact of thalamic lesions on the cortex, and will therefore help elucidate the pathophysiological mechanisms underlying the loss of psychic self-activation and other clinical syndromes that result from thalamic infarctions.

\author{
Original manuscript received 10 May 2009 \\ Revised manuscript accepted 15 September 2009 \\ First published online
}

\section{REFERENCES}

Bogousslavsky, J., Regli, F., Delaloye, B., DelaloyeBischof, A., Assal, G., \& Uske, A. (1991). Loss of psychic self-activation with bithalamic infarction. Acta Neurologica Scandinavica, 83, 309-316.

Classen, J., Schnitzler, A., Binkofski, F., Werhahn, K. J., Kim Y. S., Kessler, K. R., \& Bemecke R. (1997). The motor syndrome associated with exaggerated inhibition within the primary motor cortex of patients with hemiparetic stroke. Brain, 120, 605-619.

Darian-Smith, C., \& Darian-Smith, I. (1993). Thalamic projections to areas $3 \mathrm{a}, 3 \mathrm{~b}$, and 4 in the sensorimotor cortex of the mature and infant macaque monkey. Journal of Comparative Neurology, 335, 173-199.

Darian-Smith, C., Darian-Smith, I., \& Cheema, S. S. (1990). Thalamic projections to sensorimotor cortex in the macaque monkey: Use of multiple retrograde fluorescent tracers. Journal of Comparative Neuro$\log y, 299,17-46$.

Diez-Ariza, M., Garcia-Alloza, M., Lasheras, B., Del Rio, J., \& Ramirez, M. J. (2002). GABA A receptor antagonists enhance cortical acetylcholine release induced by $5-\mathrm{HT}_{3}$ receptor blockade in freely moving rats. Brain Research, 956, 81-85.

Di Lazzaro, V., Oliviero, A., Meglio, M., Cioni, B., Tamburini, G., Tonali, P., \& Rothwell, J. C. (2000). Direct demonstration of the effect of lorazepam on the excitability of the human motor cortex. Clinical Neurophysiology, 111, 794-799.
Di Lazzaro, V., Oliviero, A., Pilato, F., Saturno, E., Dileone, M., Mazzone, P., Insola, A., Tonali, P. A., \& Rothwell, J. C. (2004). The physiological basis of transcranial motor cortex stimulation in conscious humans. Clinical Neurophysiology, 115, 255-266.

Di Lazzaro, V., Oliviero, A., Pilato, F., Saturno, E., Dileone, M., Marra, C., Daniele, A., Ghirlanda, S., Gainotti, G., \& Tonali, P. A. (2005a). Neurophysiological predictors of long term response to AchE inhibitors in AD patients. Journal of Neurology, Neurosurgery and Psychiatry, 76, 1064-1069.

Di Lazzaro, V., Oliviero, A., Saturno, E., Dileone, M., Pilato, F., Nardone, R., Ranieri, F., Musumeci, G., Fiorilla, T., \& Tonali, P. (2005b). Effects of lorazepam on short latency afferent inhibition and short latency intracortical inhibition in humans. Journal of Physiology, 564, 661-668.

Di Lazzaro, V., Pilato, F., Di leone, M., Saturno, E., Oliviero, A., Marra, C., Daniele, A., Ranieri, F., Gainotti, G., \& Tonali, P. A. (2006). In vivo cholinergic circuit evaluation in frontotemporal and Alzheimer dementias. Neurology, 66, 1111-1113.

Engelborghs, S., Marien, P., Pickut, B.A., Verstraten, S., \& De Deyn, P. P. (2000). Loss of psychic self-activation after paramedian bithalamic infarction. Stroke, 31, 1762-1765.

Giguere, M., \& Goldman-Rakic, P. S. (1988). Mediodorsal nucleus: Areal, laminar, and tangential distribution of afferents and efferents in the frontal lobe of rhesus monkeys. Journal of Comparative Neurology, 277, 195-213.

Giorgetti, M., Bacciottini, L., Giovannini, M. G., Colivicchi, M. A., Goldfarb, J., \& Blandina, P. (2000). Local GABAergic modulation of acetylcholine release from the cortex of freely moving rats. European Journal of Neuroscience, 12, 1941-1948.

Groenewegen, H. J., \& Berendse, H. W. (1994). The specificity of the 'nonspecific' midline and intralaminar thalamic nuclei. Trends in Neuroscience, 17, 52-57.

Habib, M., \& Poncet, M. (1988). Perte de l'élan vital, de l'intérêt et de l'affectivité (syndrome athymhormique) au cours de lésions lacunaires des corps striés. Revue Neurologique, 144, 571-577.

Hallett, M. (2000). Transcranial magnetic stimulation and the human brain. Nature, 406, 147-150.

Khateb, A., Fort, P., Williams, S., Serafin, M., Muhlethaler, M., \& Jones, B. E. (1998). GABAergic input to cholinergic nucleus basalis neurons. Neuroscience, 86, 937-947.

Kujirai, T., Caramia, M.D., Rothwell, J. C., Day, B. L., Thompson, P. D., Ferbert, A., Wroe, S., Asselman, P., \& Marsden, C. D. (1993). Cortico-cortical inhibition in human motor cortex. Journal of Physiology, $471,501-520$.

Laplane, D., Baulac, M., Widlöcher, D., \& Dubois, B. (1984). Pure psychic akinesia with bilateral lesions of basal ganglia. Journal of Neurology, Neurosurgery and Psychiatry, 47, 377-385.

Liepert, J., Restmeyer, C., Munchau, A., \& Weiller, C. (2005). Motor cortex excitability after thalamic infarction. Clinical Neurophysiology, 116, 1621-1627.

Munchau, A., Orth, M., Rothwell, J. C., Di Lazzaro, V., Oliviero, A., Profice, P., Tonali, P., Pramstaller, P. P., \& Bhatia, K. P. (2002). Intracortical inhibition is reduced 
in a patient with a lesion in the posterolateral thalamus. Movement Disorders, 17, 208-212.

Oliviero, A., Leon, A. M., Holler, I., Florensa Vila, J., Siebner, H. R., Della Marca, G., Di Lazzaro, V., \& Alvarez, J. T. (2005). Reduced sensorimotor inhibition in the ipsilesional motor cortex in a patient with chronic stroke of the paramedian thalamus. Clinical Neurophysiology, 116, 2592-2598.

Rossini, P., Barker, A., Berardelli, A., Caramia, M. D., Caruso, G., Cracco, R. Q., Dimitrijevic, M. R., et al. (1994). Non invasive electrical and magnetic stimulation of the brain, spinal cord and roots: Basic principles and procedures for routine clinical application: Report of IFCN committee. Electroenceph Clinical Neurophysiology, 91, 79-92.

Sanger, T. D., Garg, R. R., \& Chen, R. (2001). Interaction between two different inhibitory systems in the human motor cortex. Journal of Physiology, 530, 307-317.

Tokimura, H., Di Lazzaro, V., Tokimura, Y., Oliviero, A., Profice, P., Insola, A., Mazzone, P., Tonali, P. A., \& Rothwell, J. C. (2000). Short latency inhibition of human hand motor motor cortex by somatosensory input from the hand. Journal of Physiology, 523, 503-513.

Vasquez, J., \& Baghdoyan, H. A. (2003). Muscarinic and $\mathrm{GABA}_{\mathrm{A}}$ receptors modulate acetylcholine release in feline basal forebrain. European Journal of Neuroscience, 17, 249-259.

Wechsler, D. A. (1987). Wechsler Memory ScaleRevised. San Antonio, TX: The Psychological Corporation.

Werhahn, K. J., Kunesch, E., Noachtar, S., Benecke, R., \& Classen, J. (1999). Differential effects on motocortical inhibition induced by blockade of GABA uptake in humans. Journal of Physiology, 517, 591-597.

Zaborszky, L., Heimer, L., Eckenstein, F., \& Leranth, C. (1986). GABAergic input to cholinergic forebrain neurons: an ultrastructural study using retrograde tracing of HRP and double immunolabeling. Journal of Comparative Neurology, 250, 282-295.

Ziemann, U., Lonnecker, S., Steinhoff, B. J., \& Paulus, W. (1996). Effects of antiepileptic drugs on motor cortex excitability in humans: A transcranial magnetic stimulation study. Annals of Neurology, 40, 367-378. 